\title{
An Investigation on Optimum Process Parameters in Terms of Surface Roughness for Turning Titanium Alloy Ti-6Al-4V Using Coated Carbide
}

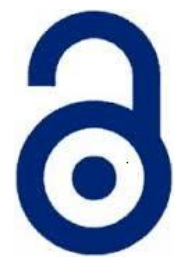 \\ Received: 20 September 2019 \\ Accepted: 20 November 2019 \\ Published: 15 December 2019 \\ Publisher: Deer Hill Publications \\ (c) 2019 The Author(s) \\ Creative Commons: CC BY 4.0
}

Abdul Md Mazid, Md Shahanur Hasan and Kazi Badrul Ahsan

\begin{abstract}
The quality of machined parts and the productivity of machining that leads to economic sustainability. These factors are also vital for machinability improvement for materials, as well as, for economically sustainable manufacturing. Due to their poor machinability titanium alloys (Ti-alloys) are categorised as difficult-to-machine materials. For the same reason products made of Ti-alloys are highly expensive and are used only in strategic and sophisticated industries. A series of real-life experimental investigations was carried out to reveal the economic optimal zones of machining parameters that can produce the best possible surface roughness in machining Ti- $6 \mathrm{Al}-4 \mathrm{~V}$ alloy, using the coated carbide cutting tools, in shortest period of operation time. As the output of the research, for using the coated carbide tools for machining the investigated Ti-alloy, optimal zones of cutting speed, feed rate and depth of cut have been proposed and presented in graphical format. The current research revealed that all three groups (with nose radius $\mathrm{N}_{\mathrm{r}}=0.4,0.8$, and $1.2 \mathrm{~mm}$ ) of coated carbide tools are capable to produce best surface finish, ranging between $R_{a}=0.5-1.0 \mu \mathrm{m}$, with cutting speed starting at $\mathrm{V}=60 \mathrm{~m} / \mathrm{min}$ and beyond at least up to $\mathrm{V}=250 \mathrm{~m} / \mathrm{min}$ while keeping the feed rate and depth of cut as constants as $f=0.1 \mathrm{~mm} / \mathrm{rev}$ and $\mathrm{d}=0.5 \mathrm{~mm}$. The data on the graphs may help researchers, engineers and manufacturers to select optimal economic cutting speed, feed rate and depth of cut to achieve a certain level of surface roughness of machined components as assigned by the product designer on the part drawing. This reduces the production cost substantially, reduces number of defect products and improves product quality for machined parts.
\end{abstract}

Keywords. Titanium alloy, machining parameters, optimisation, surface roughness, carbide tools.

\section{INTRODUCTION AND LITERATURE REVIEW}

Titanium (Ti) and Ti-alloys are non-ferrous metals possessing high "strength-versus-mass" ratio and high strength properties and toughness which are maintained even at very high temperature. The Ti-alloys possess exceptional wear and corrosion resistance in all possible hostile environments. Titanium products are expensive due to their poor machinability, as well as, extraction processes of titanium (Ti) are more complex than many other widely used metals. The major reason of applicability of Ti-alloys using in aircraft and aerospace machine building is that, the Ti-alloys have approximately one-third higher "strength-versus-mass" ratio than any other potential materials (Veiga and Davim, 2012). But it is extremely difficult to achieve desirable surface finish ( $R_{a}$ ), machining accuracy, as well as, surface quality due to the poor machinability of Ti-alloys. Machinability of materials is assessed by various factors such as the cutting tool life used for machining a material, surface roughness, surface integrity (sub-layer residual stresses, microhardness, and metallographic phase stability), part geometry and dimensional accuracy obtained, amount of heat generated in the cutting zone, cutting forces developed and material removal rate (MRR) and amount of electrical energy required for machining (Machado and Walbank, 1990; Rahman et al., 2003; Ezugwu and Wang, 1997; Davim, 2010; Yang and Liu, 2007; Ogedengbe, 2019). Mechanical and metallurgical properties of materials largely contribute to their machinability (Davim, 2010). During machining of Ti-alloys using conventional cutting tools at the range of cutting speed $V=60-75 \mathrm{~m} / \mathrm{min}$ it demonstrates very high cutting tool wear rate. Some researchers suggested, using carbide, ceramic, and diamond cutters for cutting Ti-alloys, higher cutting speeds can be achieved (Gatto and luliano, 1997). But at higher cutting speed and under high temperature growth at the cutting zone, several researchers (Machado and Walbank, 1990; Rahman et al., 2003; Ezugwu and Wang, 1997; Yang and Liu, 2007; Hua and Shivpuri, 2004) expressed opinion that these tool materials exhibit increased chemical reactivity with titanium atoms. As stated by Veiga et al (2012) and other researchers low heat transition rate (varying in the

Abdul Md Mazid ${ }^{1}$ ه, Md. Shahanur Hasan² and Kazi Badrul Ahsan ${ }^{3}$

School of Engineering and Technology, Central Queensland University, Australia

E-mails: ${ }^{1}$ a.mazid@cqu.edu.au; ${ }^{2}$ m.hasan@cqu.edu.au; ${ }^{3}$ kazi.badrul@yahoo.com

Reference: Mazid, M. A., Hasan, M. S. and Ahsan, K. B. (2019). An Investigation on Optimum Process Parameters in Terms of Surface Roughness for Turning Titanium Alloy Ti-6Al-4V Using Coated Carbide. International Journal of Engineering Materials and Manufacture, 4(4), 137-145. 
range of $5.5 \mathrm{~W} / \mathrm{mK}$ to $19.0 \mathrm{~W} / \mathrm{mK}$ in variation of temperature ranging from room temperature to $800^{\circ} \mathrm{C}$, while that is approximately $43 \mathrm{~W} / \mathrm{mK}$ for carbon steels) of Ti-alloys causes the high heat generation in cutting zone, which in turn adversely affects the surface finish, residual stress growth and phase transformation in the sub-layer machined surface.

Due to its very high cost (manufacturing and material), Ti-alloys have limited applications only within aircraft, spacecraft, medical devices and surgery, motorsport, premium sports equipment, consumer electronics and defence industries (Rahman et al., 2003; Ezugwu and Wang, 1997). Manufacturing cost can be reduced substantially if optimal economic machining parameters are used for machining. Poor machinability of Ti and Ti-alloys was noted in Europe, America and Russia starting from their early applications after The World War II. Due to several disadvantages and complexities in all phases of processing application of Ti-alloys for general purpose machine building is still a luxurious topic. High reactivity with sulphur, carbon, oxygen, and nitrogen, forming insoluble compounds and sequestering them in slag makes the machinability of $\mathrm{Ti}$ and $\mathrm{Ti}$-alloys poorer. Poor machinability of $\mathrm{Ti}$ and Ti-alloys is now a global problem that worth to study, in depth, with a notion to develop optimal economic cutting parameters/regimes/conditions and machining processes, adequate cutting tool materials, adequate machine tools selection and jigs-fixtures that can yield cheaper and more affordable $\mathrm{Ti}$ and Ti-alloys products. Although applications of Ti-alloys started in Europe, America and Russia just after World War II, unfortunately not significant achievement in their machining has been achieved. That is why Ti-alloys are not widely used in general machine building and many other engineering purposes.

The major goal of the current research project was set to establish optimal economic cutting regimes/parameters (optimal zones of cutting speed $(\mathrm{V} \mathrm{m} / \mathrm{min})$, feed rates ( $\mathrm{mm} / \mathrm{rev}$ ) and optimal depth of cut ( $\mathrm{d} \mathrm{mm}$ )) for the most commonly used in aerospace machine building $\alpha-\beta$ Ti-alloy, Ti-6Al-4V, using widely available coated carbide cutting tools with variable nose radius. This works was performed by the way of physical experimentation. The series of experiments is supposed to be repeated several times until the stable data are achieved. The advantage of this method is that the results obtained are purely physical (and not simulation based) taking into account all real-life scenario of machining process and the method is reliable though a bit laborious and time consuming. The method does not use any assumed or accepted data but all of the physical situation of the cutting process, the workpiece material, machine tool and the cutting tool conditions. The optimal cutting regimes will certainly help manufacturing industries to produce parts with least possible manufacturing cost and to reduce number of defect products, thus leading to economic sustainability.

\section{RELEVANT BACKGROUND}

\subsection{Titanium Alloys - A Briefing}

Pure Titanium (Ti) is not suitable for using it in machine building purposes because it changes rapidly its microstructural phase with the change of temperature; the process is called allotropic transformation. At about $882^{\circ} \mathrm{C}$ temperature Ti undergoes an allotropic transformation changing from alpha-phase ( $\alpha$-phase) to beta-phase ( $\beta$-phase) that affects the overall physio-mechanical properties of materials (Rahman et al., 2003; Ezugwu and Wang, 1997; Yang and Liu, 2007). Some additional inclusions to pure Ti allow manipulating the allotropic temperature towards positive side of its applications. These inclusions are called stabilisers and the stabilisers for Ti-alloys are classified according to phase as follows (Veiga and Vadim, 2012; Machado and Walbank, 1990):

- Alpha ( $\alpha$ ) stabilising elements: Al, O, N, and C; these inclusions help to increase the temperature of allotropic transformation preventing phase transformation which in turn improves the usability of Ti-alloys;

- Beta ( $\beta$ ) stabilising elements: $\mathrm{Mo}, \mathrm{Cr}, \mathrm{Mn}, \mathrm{Ni}, \mathrm{V}, \mathrm{Fe}, \mathrm{Nb}, \mathrm{Cu}$, and Si; these elements help to decrease temperature of phase transformation;

- Neutral stabilisers/elements: Sn and Zr and these do not have much influence on temperature transformation.

Accordingly, Ti and Ti-alloys are classified into following four main groups:

- Unalloyed Ti that has excellent corrosion resistance but lower strength properties.

- Alpha $(\alpha)$ and near-alpha alloys: these alloys contain $\alpha$-stabiliser and it produces excellent creep resistance.

- Alpha-beta $(\alpha-\beta)$ alloys: these alloys contain mixture of both alpha and beta stabilisers and have the largest application in aerospace machine building; Ti-6Al-4V is the most common and popular alloy in this group.

- Beta alloys ( $\beta$ ): these alloys contain significant quantities of beta-stabilisers and produce high density accordingly high hardness.

Among all titanium alloys, $\alpha-\beta$ alloy Ti-6Al-4V has higher application (about $60 \%$ of all titanium products) in aircrafts, jet engines, racing cars, high performance reciprocating engines, compressor disks, gas turbine engines, casing, etc (Ezugwu et al., 2003; Ezugwu and Wang, 1997). On top of the mentioned properties, the important one of these alloys, suitable in these applications, is high fatigue strength. Titanium parts manufactured by turning operations are often shafts subjected to cyclic loading, for which fatigue and pulsating fatigue strength is vital. Titanium is also often used for high temperature applications, at which the fatigue strength of the materials drops significantly (Davim, 2010). It is therefore important that appropriate manufacturing processes are utilised that do not significantly reduce the fatigue properties of the parts. The surface roughness of a component affects its fatigue strength (Ataollah J., et al., 2008). Higher surface roughness increases crack initiation which eventually decreases fatigue strength. 


\subsection{Parameters for Quality Machined Products}

In machine manufacturing industry the quality of machined parts is assessed by the three major physical parameters which are surface roughness, sub-surface integrity, and geometric and dimensional accuracy. All these parameters must have to be satisfied for a part to be accepted as good. Deviation of any of these parameters makes the part to be rejected and not to be used in assembly of a machine unit. From early ages of machine manufacturing it has been well accepted that the surface quality (surface roughness and sub-surface integrity) plays a vital role in the industry. This has been again stated recently by Ancio et al. (2015) proficiently.

Required surface roughness values or class of surface roughness is assigned by the designer on the part/detail drawings. Assigning unnecessary higher class of surface roughness makes a product unnecessary costly; this may increase the production cost of a machine and may hinder sustainability of a company. Similarly, it is also essential to select a suitable machine tool for machining a part that is capable to achieve the designed surface roughness with cost effectiveness. The level of sub-surface residual stresses developed by the action of cutting forces and generated heat decide the surface integrity of machined parts. These may cause dislocation in crystal lattice of metal causing eventually micro-crack development which in turn adversely affects the fatigue life of a part. Phase transfer in crystal structure is also possible in some cases due to the same reasons, which affects the microstructure of metal affecting the surface integrity of machine parts (Schneider, F. et al., 2016). Required geometric shape and dimensional accuracy are essential for assembly purposes for functionality of the machine unit. Functional dimensions of a part are designed with necessary tolerances for fit and suitable class of surface roughness. Again, it is mentionable that unnecessary lower level of tolerances or better surface roughness makes it difficult to achieve the assigned level. Certainly, this increases the production cost unnecessary and unwisely and companies may need to compromise with economic sustainability.

\section{EXPERIMENTAL METHODOLOGY}

It has been indicated by Astakhov (1999) in his book Metal Cutting Mechanics so appropriately that manufacturing industries rely completely on the thumb-rule empirical machining parameters provided by the cutting tool manufacturers. And they must rely on them because they are not supposed to have enough opportunity of scientific support for the better way out which could provide best possible quality and least possible manufacturing cost. These provided data cover a wider range of applications of their products for their larger commercial interest. But experience and observations have shown that these data barely satisfy the exactly required machining parameters (for a certain material using a certain cutting tool) which can yield the best possible machining quality (surface roughness and surface integrity) and least possible machining time and manufacturing cost. As the literature survey shows that a huge amount of works has been dedicated to the machinability assessment of various metals and alloys during the past twenty to thirty years, but not much concentration has been deployed on optimal economic machining parameters (in the sense of both better machining quality and lower machining costs) unfortunately. Again, there have been a good amount of research works on optimisation of machining parameters published but most of them are simulation (Kuttolmadom M., et al., 2017) or empirical and statistical model based and these do barely present the real case scenario of physical machining process of a material using a certain cutting tool with certain geometry.

Out of others, the repetitive physical machining methodology can provide more accurate and proficient results for determining optimal economic machining parameters for individual cutting tool for machining a certain material. This involves a series of time consuming and laborious experimental investigation that carries on a series of real-life machining experiments with many samples. The major advantage of this methodology is that this takes into consideration all involved details, properties, scenario and parameters of the machining process and thus it is possible to avoid unknown effects of the system. In brief, this methodology involves machining of samples with a set of cutting parameters $(V, f, d)$. In each machining operation, for a batch of samples, one of the parameters (such as $V$ ) is varied in a large range (covering all possible values) but keeping the rest two parameters ( $f$ and $d$ ) constant for the first instant. The obtained surface roughness values $\left(R_{a}\right.$ or $\left.R_{z}\right)$ for each of the machined samples should be measured in three lines (approximately at an equal distance and in reality, it is at every $120^{\circ} \mathrm{C}$ around the circumference) along the axis of a sample around the cylindrical machined surface. The average of the three values of $R_{a}\left(\right.$ or $R_{z}$ ) is the acceptable value for surface roughness obtained for the investigated sample. The several experimented values of $V$ and obtained respectable values of $\mathrm{R}_{\mathrm{a}}$ should be plotted on a graph. This graph should show a zone of acceptable optimal values of $\mathrm{V}$.

In the second stage, the next batch of samples is machined varying a second parameter (such as $f$ ) while the rest two parameters $(V$ and $d$ ) are kept constant. But this time the value of the constant $V$ should be accepted from the previously obtained from the zone of optimal values of V. Similarly, the cycle of experimentation process should continue repeatedly a number of times until a satisfactory range of optimal cutting parameters $(V, f, d)$ is achieved. Despite it is a laborious and long process, the output obtained should be a reasonably perfect one, because every influential factor participating in the machining process is considered naturally. The practicality of the methodology and the essence of it have been recently demonstrated in the research output of a final year mechanical engineering student's project supervised by the first author. In his project the student investigated the variation of production cost for machining of a mild steel stepped shaft. The shaft was machined using the optimal economic machining parameters developed by the proposed physical machining method and that produced in local manufacturing 
companies. The student stated in his project report: “The production costing process and comparisons determined that the resulting cost of the specified component was on average $\$ 161.11$ for production at the university engineering workshop using optimised cutting parameters compared to an average of $\$ 226.36$ for local engineering manufacturing companies."

The above example clearly evidenced the financial benefit of the stated physical machining methodology for machining parameter optimisation. Procedures of the methodology are described in the following sections of experimentation.

\section{EXPERIMENTAL INVESTIGATION}

To accomplish the planned experiments using the real-life physical machining methodology the resources used are in-home available Lathe Harrison M400 for turning operations and Taylor Hobson Surtronic 3+ instrument - HB 103 for surface roughness assessment. These resources, in performances, are shown in Figures 1 and 2 respectively. The 3-jaw self-centred chuck for universal lathes was used to clamp the $\phi 50 \mathrm{~mm}$ diameter Ti-6Al-4V shaft of length $450 \mathrm{~mm}$ on the Harrison M400 lathe for turning operations as shown in Figure 1. The lathe is driven by $7.5 \mathrm{KW}$ motor which provides $1500 \mathrm{rpm}$. This lathe has a wide scope to set up cutting parameters, including eighteen different rotational speeds which range from 40 to $2000 \mathrm{rpm}$, and fifteen feed rate options ranging from 0.04 to $2.84 \mathrm{~mm} / \mathrm{rev}$. As it is usually used for Ti-alloys machining in the industry and easily available, SECO TS2000 coated carbide inserts have been used for experiments. The specifications of these coated carbide inserts are CNMC 120404-MF1, TS2000 (8 cutting edge), CNMC 120408-MF1, TS2000 (8 cutting edge, and CNMC 120412-MF4, TS2000 (8 cutting edge) with nose radii $0.4 \mathrm{~mm}, 0.8 \mathrm{~mm}$ and $1.2 \mathrm{~mm}$ respectively. The tool holder used (Figure 3 ) for mounting the cutting insert was of SECO model PCLNR2525M12JET.

Geometry of the inserts used, mentioned above, was as rake angle $-6^{\circ}$, inclination angle $-6^{\circ}$, lead angle $95^{\circ}$, clearance angle $0^{\circ}$, nose angle $80^{\circ}$ and nose radius $0.4 \mathrm{~mm}, 0.8 \mathrm{~mm}$ and $1.2 \mathrm{~mm}$ with chip breaker. During the machining process a cutting fluid of Caltex (Trusol GP), as available, has been applied to keep the cutting zone free from excessive heat and to reduce friction and easy swarf removal. The Ti-6Al-4V $\$ 50 \mathrm{~mm}$ diameter bar under investigation was marked to divide it into samples of $25 \mathrm{~mm}$ length (Figure 4) and the samples were given arbitrary sample numbers. The Surtronic $3+$ instrument was used for measuring values of surface roughness $\left(R_{a}\right)$ on each machined surface of the Ti-alloy bar (Figure 2). This instrument uses stylus type technology and it is a portable and self-contained machine for use in both workshop and laboratory and is able to measure the surface finish of machined components with high enough accuracy. Technical specifications of the Surtronic 3+ instrument are: maximum traverse length: $25.4 \mathrm{~mm}$, cut-off values $(\mathrm{mm}): 0.25,0.8,2.5 \mathrm{~mm}$, evaluation lengths are $\times 1, \times 3, \times 5, \times 10$ cut-off length, parameters available: $R_{a}, R_{a}, R_{z}(D I N), R_{y}, S_{m}$; filter types: ISO-2CR or Gaussian selectable, Traverse speed: 1 $\mathrm{mm} / \mathrm{sec}$. As planned, three series of experiments have been conducted, one for each of the accepted nose radii 0.4 $\mathrm{mm}, 0.8 \mathrm{~mm}$, and $1.2 \mathrm{~mm}$.

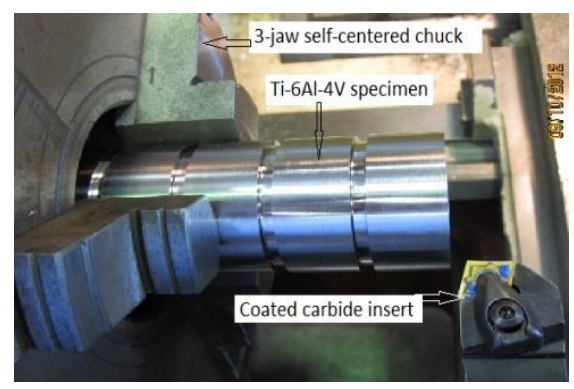

Figure 1: Machining experiment on Harrison M400

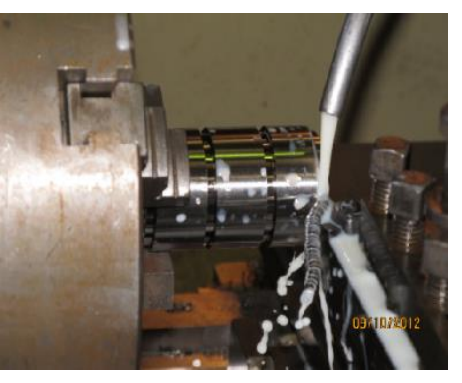

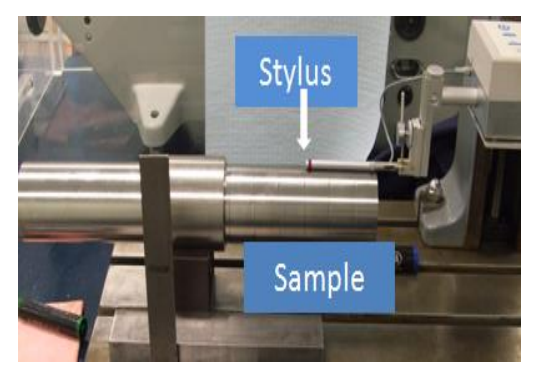

Figure 2: Surface roughness assessment using Surtronic 3+

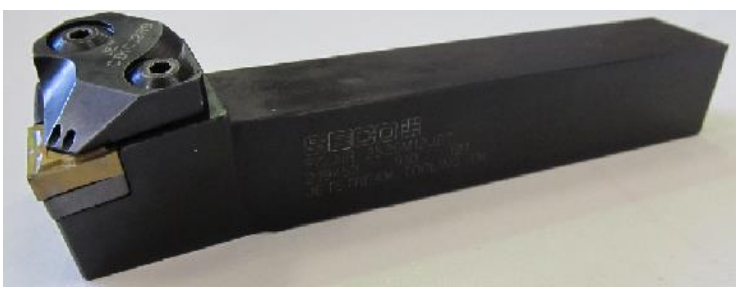

Figure 3: A coated carbide inserts clamped in the tool holder

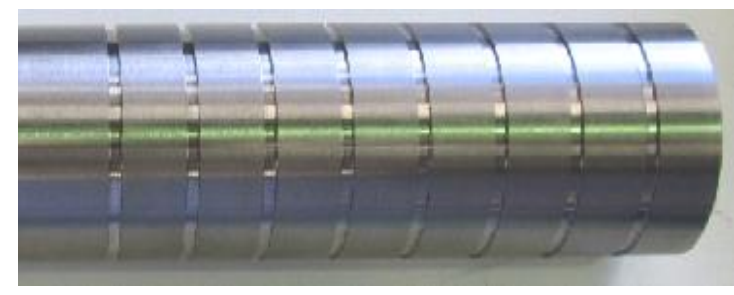

Figure 4: One half of the Ti-6Al-4V specimen bar 


\subsection{Experiment for Economic Cutting Speed Zone for Variable Nose Radius}

For the first series of experiments the samples ( 8 samples $\times 3$ groups) of the Ti-6Al-4V bar were machined with various cutting speeds ranging within $V=12-250 \mathrm{~m} / \mathrm{min}$ using the coated carbide inserts with nose radii $\mathrm{N}_{\mathrm{r}}=0.4 \mathrm{~mm}, \mathrm{~N}_{\mathrm{r}}$ $=0.8 \mathrm{~mm}$, and $\mathrm{N}_{\mathrm{r}}=1.2 \mathrm{~mm}$ while keeping the feed rate $(\mathrm{f}=0.1 \mathrm{~mm} / \mathrm{rev})$ constant and the constant depth of cut $(\mathrm{d}=0.5 \mathrm{~mm}$ ) for all of the samples. As the draft tabulated data (not included in this paper) display there been twenty-four samples machined for three groups of experiments. Three surface roughness values $\left(R_{a}\right)$ around the circumference for each of the samples were measured using the mentioned Surtronic 3+ instrument (Figure 2). The average of these $R_{a}$ values was calculated for each of the machined samples and accepted as the effective value of $R_{a}$ in $\mu \mathrm{m}$. The graphs in Figure. 5 show the relationship of obtained values of surface roughness $\left(R_{a}\right)$ for various cutting speeds $(V)$ used. As the graphs reveal, the optimal cutting speed zone $\left(V_{o p t}\right)$ for Ti-6Al-4V samples ranges roughly between the values of $V=60-160 \mathrm{~m} / \mathrm{min}$ for the coated carbide cutter with all three different nose radii. The parameters for this series of experiments are presented below in the following Table 1 for easy and comprehensive understanding.

\subsection{Experiment for Optimal Feed Rate Zone for Variable Nose Radius}

For the second series of experiments the samples ( 6 samples $\times 3$ groups) of the Ti-6Al-4V bar were machined similarly with coated carbide inserts with variable nose radius $(\mathrm{Nr}=0.4 \mathrm{~mm}, 0.8 \mathrm{~mm}$ and $1.2 \mathrm{~mm})$. But this time the feed rates were varied ranging within $f=0.04-0.28 \mathrm{~mm} / \mathrm{rev}$ since optimal feed rates were seeking this time. The cutting speed $(V=80 \mathrm{~m} / \mathrm{min}$ ) was kept constant for the cutter with $\mathrm{Nr}=0.4 \mathrm{~mm}$ since in the first stage of experiments it was revealed that $V=80 \mathrm{~m} / \mathrm{min}$ (within the zone) was the speed providing the best surface roughness (Figure 5a) amongst all of the investigated speeds and the constant depth of cut $(\mathrm{d}=0.5 \mathrm{~mm})$ as in the previous case. Similarly cutting speeds $V=50 \mathrm{~m} / \mathrm{min}$ and $\mathrm{V}=60 \mathrm{~m} / \mathrm{min}$ were kept constant for the machining operations performed using coated carbide cutters with nose radii $\mathrm{Nr}=0.8 \mathrm{~mm}$ and $\mathrm{Nr}=1.2 \mathrm{~mm}$ respectively. Note that depth of cut was kept constant $(\mathrm{d}=0.5 \mathrm{~mm})$ for all of these three groups of samples for turning operations.
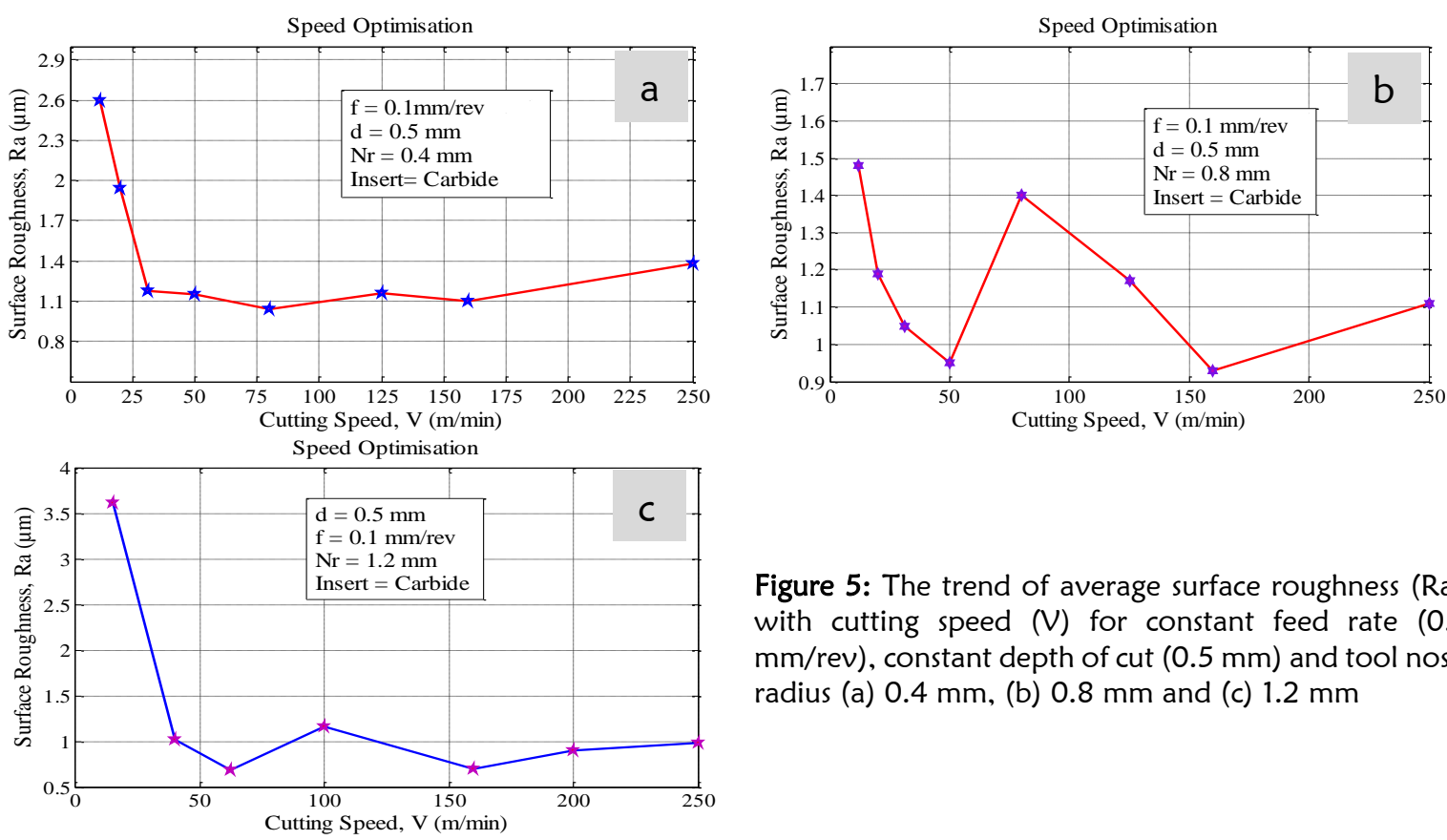

Figure 5: The trend of average surface roughness $(\mathrm{Ra})$ with cutting speed $(V)$ for constant feed rate $(0.1$ $\mathrm{mm} / \mathrm{rev})$, constant depth of cut $(0.5 \mathrm{~mm})$ and tool nose radius (a) $0.4 \mathrm{~mm}$, (b) $0.8 \mathrm{~mm}$ and (c) $1.2 \mathrm{~mm}$

Table 1: Operational data for cutting speed optimisation

\begin{tabular}{|c|c|c|c|c|c|}
\hline $\begin{array}{c}\text { Nose radius } \\
\mathrm{N}_{\mathrm{r}}(\mathrm{mm})\end{array}$ & $\begin{array}{l}\text { Depth of cut } \\
\text { (d) }(\mathrm{mm})\end{array}$ & $\begin{array}{c}\text { Feed rate }(\mathrm{f}) \\
(\mathrm{mm} / \mathrm{rev})\end{array}$ & $\begin{array}{l}\text { Cutting speed }(\mathrm{V}) \\
\text { variable, }(\mathrm{m} / \mathrm{min})\end{array}$ & $\begin{array}{l}\text { Surface roughness } \\
\left(\mathrm{R}_{\mathrm{a}}\right)(\mu \mathrm{m})\end{array}$ & Comments \\
\hline 0.4 & 0.5 & 0.1 & \multirow{3}{*}{$\begin{array}{l}\text { Variable values in } \\
\text { the range } V=25 \text { - } \\
250 \mathrm{~m} / \mathrm{min} \text { as in } \\
\text { Fig } 5\end{array}$} & \multirow{3}{*}{$\begin{array}{l}\text { Measured values } \\
\text { showed in Fig. } 5\end{array}$} & $\begin{array}{l}\mathrm{V}=50-160 \mathrm{~m} / \mathrm{min} \\
\text { provide better } \mathrm{R}_{\mathrm{a}}\end{array}$ \\
\hline 0.8 & 0.5 & 0.1 & & & $\begin{array}{l}\mathrm{V}=50 \mathrm{~m} / \mathrm{min} \\
\text { provides better } \mathrm{R}_{\mathrm{a}}\end{array}$ \\
\hline 1.2 & 0.5 & 0.1 & & & $\begin{array}{l}\mathrm{V}=50-250 \mathrm{~m} / \mathrm{min} \\
\text { provide better } \mathrm{R}_{\mathrm{a}}\end{array}$ \\
\hline
\end{tabular}


Similarly, the average surface roughness data $\left(R_{a}\right)$ for each of the eighteen samples were measured using the Taylor Hobson Surtronic 3+ instrument and the average data were accepted for $R_{a}$. The graphs in Figure 6 shows the relationship of obtained values of surface roughness $\left(R_{a}\right)$ for various feed rates $(f)$ for machining Ti-6Al-4V using the coated carbide cutters with several nose radii $(\mathrm{Nr}=0.4 \mathrm{~mm}, 0.8 \mathrm{~mm}$ and $1.2 \mathrm{~mm})$. The parameters for this series of experiments are summarised below in the following Table 2 for easy and comprehensive understanding.

\subsection{Experiment for Optimal Depth of Cut with Variable Nose Radius}

In the third series of experiments, in the similar way as above described, machining of Ti-6Al-4V samples were carried out using the coated carbide inserts with nose radius $\mathrm{N}_{r}=0.4 \mathrm{~mm}$, but this time keeping the cutting speed $(V)$ and feed rate (f) values constant. These constant values were $V=80 \mathrm{~m} / \mathrm{min}$ and $f=0.1 \mathrm{~mm} / \mathrm{rev}$ (Figures $5 \mathrm{a}$ and $6 \mathrm{a}$ respectively) since these were established to be the top parameters providing the best surface finish in stage one and stage two of experiments for the cutting tool nose radius $\mathrm{N}_{\mathrm{r}}=0.4 \mathrm{~mm}$. In this case the depth of cut was varied within possible values ranging $d=0.08-1.6 \mathrm{~mm}$. The surface roughness data were measured, similarly as earlier, for the investigated samples using the Taylor Hobson Surtronic $3+$ instrument and the average $R_{a}$ data were calculated for each of the samples.

Exactly in the same manner another two groups of experiments were carried out, one for the coated carbide inserts with $\mathrm{Nr}=0.8 \mathrm{~mm}$ using $\mathrm{V}=50 \mathrm{~m} / \mathrm{min}$ (optimal as revealed, referring to Figure 6) and another for using the coated carbide inserts with $\mathrm{Nr}=1.2 \mathrm{~mm}$ while the cutting speed was $V=60 \mathrm{~m} / \mathrm{min}$ as optimal referring to Figure $5 c$. All the obtained data from the experiments were carefully tabulated and graphs have been produced for visual and comprehensive understanding.
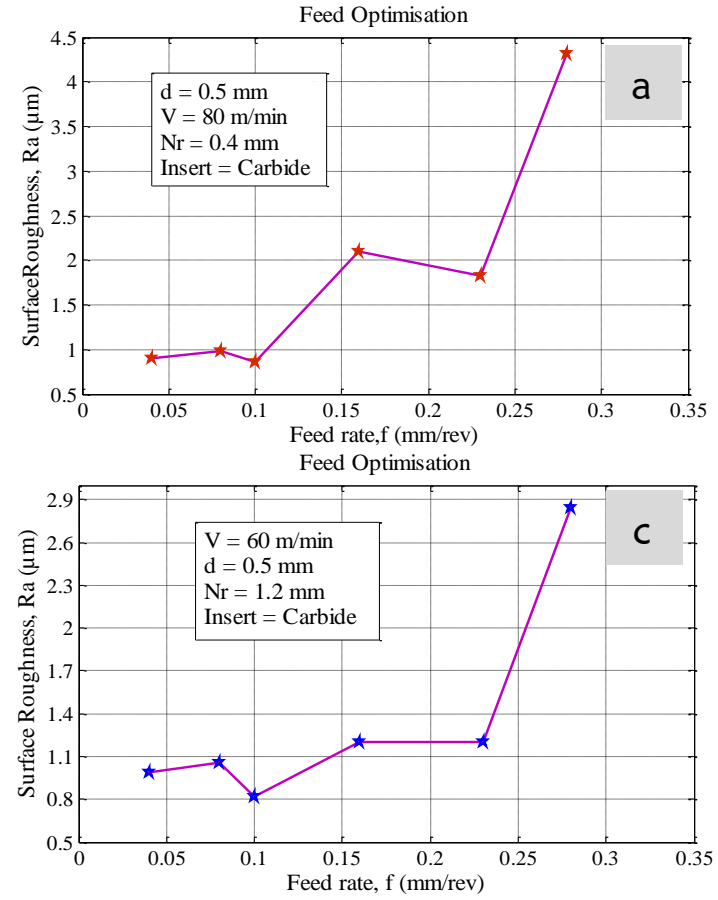

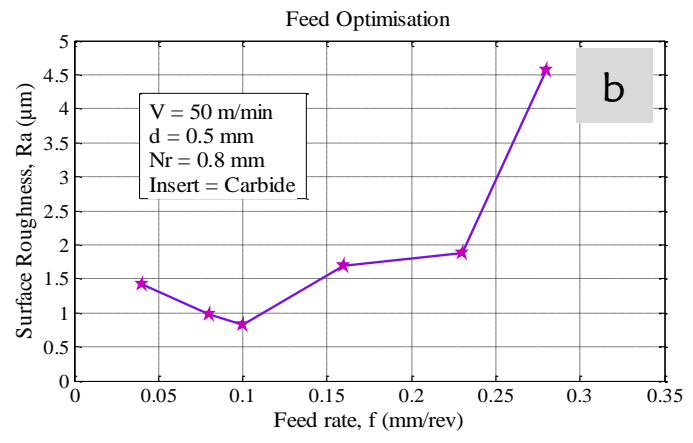

Figure 6: The trend of average surface roughness $(\mathrm{Ra})$ with feed rate (f) for constant depth of cut $(0.5 \mathrm{~mm})$ and (a) nose radius $0.4 \mathrm{~mm}$ and cutting speed 80 $\mathrm{m} / \mathrm{min}$, , (b) nose radius $0.8 \mathrm{~mm}$ and cutting speed 50 $\mathrm{m} / \mathrm{min}$, and (c) nose radius $0.1 .2 \mathrm{~mm}$ and cutting speed $60 \mathrm{~m} / \mathrm{min}$

Table 2: Operational data for feed rate optimisation

\begin{tabular}{|c|c|c|c|c|c|}
\hline $\begin{array}{c}\text { Nose radius } \\
N_{r}(\mathrm{~mm})\end{array}$ & $\begin{array}{l}\text { Cutting speed } \\
(\mathrm{V})(\mathrm{m} / \mathrm{min})\end{array}$ & $\begin{array}{l}\text { Depth of cut } \\
\text { (d) (mm) }\end{array}$ & $\begin{array}{l}\text { Feed rate }(\mathrm{f}) \\
(\mathrm{mm} / \mathrm{rev})\end{array}$ & $\begin{array}{l}\text { Surface roughness } \\
\left(\mathrm{R}_{a}\right)(\mu \mathrm{m})\end{array}$ & Comments \\
\hline 0.4 & 80 & & & & $\begin{array}{l}R_{a} \text { stays same up-to } f \\
=0.1, \text { then increases } \\
\text { linearly }\end{array}$ \\
\hline 0.8 & 50 & 0.5 & $\begin{array}{c}\text { Variable, as } \\
\text { shown in Fig. 6) }\end{array}$ & $\begin{array}{c}\text { Measured values } \\
\text { (Fig.6) }\end{array}$ & $\begin{array}{l}R_{a} \text { decreases up-to } f= \\
0.1 \text {, then increases } \\
\text { linearly }\end{array}$ \\
\hline 1.2 & 60 & & & & $\begin{array}{l}f=0.1 \text { provides the } \\
\text { best } R_{a}\end{array}$ \\
\hline
\end{tabular}



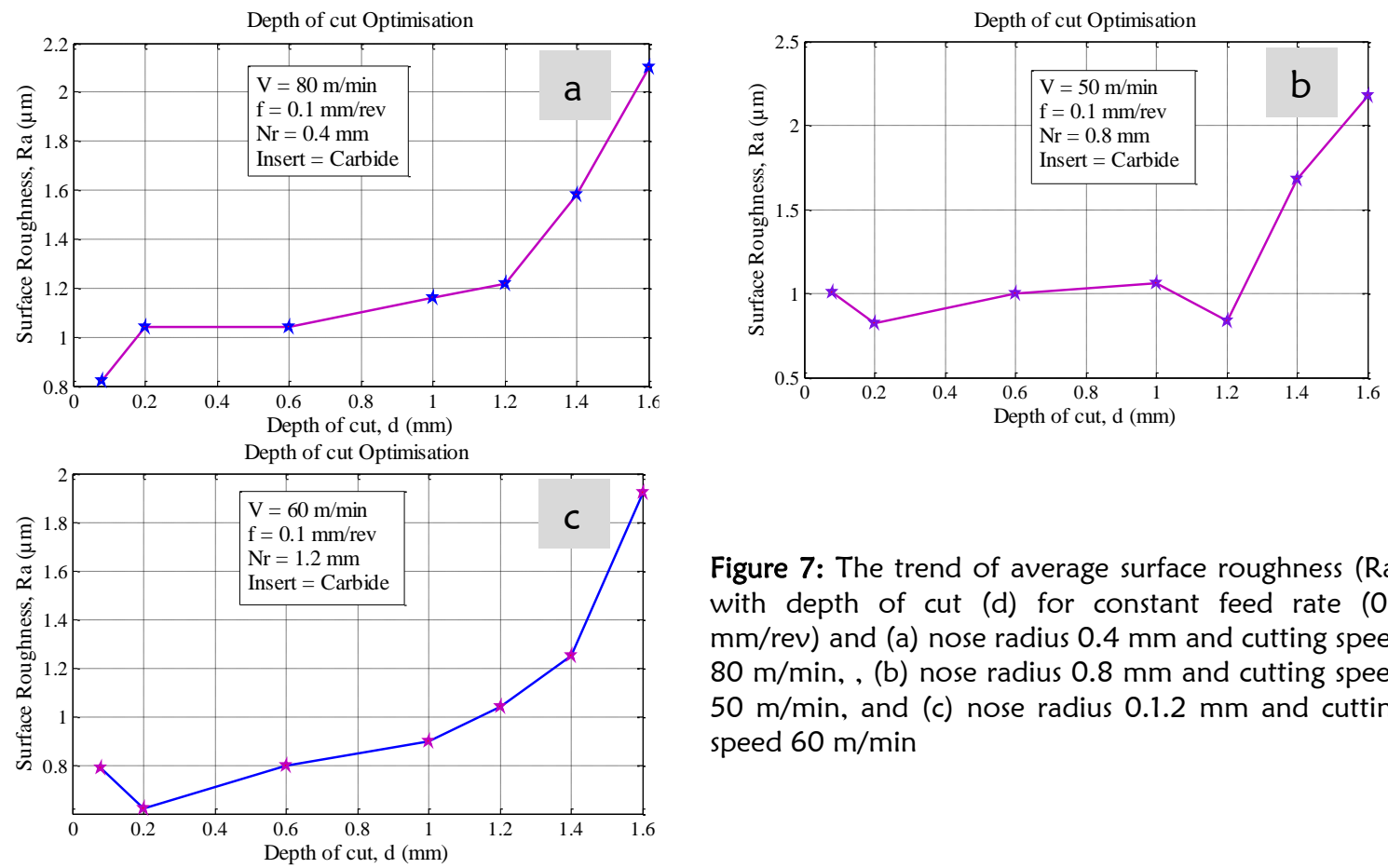

Figure 7: The trend of average surface roughness $(\mathrm{Ra})$ with depth of cut (d) for constant feed rate (0.1 $\mathrm{mm} / \mathrm{rev}$ ) and (a) nose radius $0.4 \mathrm{~mm}$ and cutting speed $80 \mathrm{~m} / \mathrm{min}$, , (b) nose radius $0.8 \mathrm{~mm}$ and cutting speed $50 \mathrm{~m} / \mathrm{min}$, and (c) nose radius $0.1 .2 \mathrm{~mm}$ and cutting speed $60 \mathrm{~m} / \mathrm{min}$

Table 3: Operational data for feed rate optimisation

\begin{tabular}{cccccc}
\hline $\begin{array}{c}\text { Nose } \\
\text { radius } N_{r} \\
(\mathrm{~mm})\end{array}$ & $\begin{array}{c}\text { Cutting speeds } \\
(\mathrm{V})(\mathrm{m} / \mathrm{min})\end{array}$ & $\begin{array}{c}\text { Feed rates }(\mathrm{f}) \\
(\mathrm{mm} / \mathrm{rev})\end{array}$ & $\begin{array}{c}\text { Depth of cut } \\
(\mathrm{d})(\mathrm{mm})\end{array}$ & $\begin{array}{c}\text { Surface roughness } \\
\mathrm{R}_{\mathrm{a}}(\mu \mathrm{m})\end{array}$ & Comments \\
\hline 0.4 & 80 & & & & $\begin{array}{l}\mathrm{d}=0.1-0.6 \mathrm{~mm} \text { provide } \mathrm{R}_{\mathrm{a}} \\
=1.02 \mu \mathrm{m}\end{array}$ \\
0.8 & 50 & 0.1 & $0.08-1.6$ & $\begin{array}{c}\text { Measured } \\
\text { parameter (Fig. 7) }\end{array}$ & $\begin{array}{l}\mathrm{d}=0.2-1 \mathrm{~mm} \text { provide } \mathrm{R}_{\mathrm{a}}= \\
0.8-1.05 \mu \mathrm{m}\end{array}$ \\
& & & & $\begin{array}{l}\mathrm{d}=0.2-1 \mathrm{~mm} ; R_{\mathrm{a}} \text { increases } \\
\text { linearly from } 0.2 \text { to } 1.01 \mu \mathrm{m}\end{array}$ \\
\hline
\end{tabular}

The graphs in Figure 7 show the relationship of obtained values of surface roughness $\left(R_{a}\right)$ for several depth of cut for machining Ti-6Al-4V using the coated carbide cutters with several nose radii as $\mathrm{Nr}=0.4 \mathrm{~mm}, 0.8 \mathrm{~mm}$, and $1.2 \mathrm{~mm}$. The parameters for this series of experiments are given in Table 3 for easy and comprehensive understanding. The cumulative results of real-life experiments for cutting speed optimisation of Ti-alloy, using popular coated carbide tools, are discussed in the following section.

\section{EXPERIMENTAL RESULTS AND DISCUSSIONS}

As mentioned earlier that there are so many known and unknown factors influencing cutting processes that it is only possible to achieve the best results if the research is carried out by real-life experiments in metal machining in real environment. Because it is only possible to take into account all influencing factors with natural appearances in the case of real-life experiments. In any other way it is certain that many influencing factors on metal machining processes may be disregarded leading to less accurate outcomes.

As described in the procedures of experiments in previous section that a series of real-life turning operations have been carried out with variable cutting parameters ( $V$, f, d) using coated carbide inserts (CNMG 120404-MF1, TS2000 (8 cutting edge), CNMC 120408-MF1, TS2000 (8 cutting edge, and CNMC 120412-MF4, TS2000 (8 cutting edge) with nose radii $0.4 \mathrm{~mm}, 0.8 \mathrm{~mm}$ and $1.2 \mathrm{~mm}$ respectively on the universal Harrison $\mathrm{M} 400$ lathe machine. The surface roughness $\left(R_{a}\right)$ values of machined samples, prepared with several cutting parameters/regimes, were measured using the precision Taylor Hobson Surtronic 3+ equipment at room temperature. All of the data such as parameters of cutting regimes and the obtained surface roughness values were scrupulously tabulated in a number of tables. The obtained data were plotted in graphical forms as displayed in Figures 5-13, each group of three graphs belonging to each of the three nose radii $\left(\mathrm{N}_{\mathrm{r}}=0.4 \mathrm{~mm}, \mathrm{~N}_{\mathrm{r}}=0.8 \mathrm{~mm}\right.$ and $\left.\mathrm{N}_{\mathrm{r}}=1.2 \mathrm{~mm}\right)$ were investigated. Graphs on Figures 5 , exhibiting the output of experiments with nose radii $\mathrm{N}_{\mathrm{r}}=0.4 \mathrm{~mm}, \mathrm{~N}_{\mathrm{r}}=0.8 \mathrm{~mm}$, and $\mathrm{N}_{\mathrm{r}}=1.2 \mathrm{~mm}$ respectively, 
demonstrate the results of surface roughness $\left(R_{a}\right)$ obtained in terms of variable cutting speeds $(V)$ while keeping the feed rates ( $f$ ) and depths (d) of cut constant throughout these experiments. The graphs reveal that the coated carbide inserts with $\mathrm{N}_{\mathrm{r}}=1.2 \mathrm{~mm}$ produces better surface finish in relation to coated carbide inserts with $\mathrm{N}_{\mathrm{r}}=0.4 \mathrm{~mm}$ and $\mathrm{N}_{\mathrm{r}}=0.8 \mathrm{~mm}$. The insert with $\mathrm{N}_{\mathrm{r}}=0.4 \mathrm{~mm}$ produces the roughest surface finish out of these three options. Overall, it has been found that all of these three inserts of coated carbide produce much rougher surface finish for machining Ti-6Al-4V at lower, somewhere below $75 \mathrm{~m} / \mathrm{min}$, cutting speeds, as the cutting speeds go lower and lower it produced rougher and rougher surfaces on machined $\mathrm{Ti}-6 \mathrm{Al}-4 \mathrm{~V}$ alloy samples.

There is some unexpected result in the near zone of cutting speed $V=100 \mathrm{~m} / \mathrm{min}$, unusually surface roughness has gone higher for the coated carbide inserts with nose radius $\mathrm{N}_{r}=0.8 \mathrm{~mm}$ and $\mathrm{N}_{r}=1.2 \mathrm{~mm}$ (Figure 6). At this stage of research unlikely any explanation of this phenomenon can be given, but this can be postulated to be related to the reactivity of $\mathrm{Ti}$ atoms with atoms of materials of the carbide inserts, as was stated by some researchers (Machado and Walbank, 1990; Rahman et al., 2003). The graphs on Figure 6 exhibits the results of machining experiments with variable feed rates while depth of cut and the cutting speeds were kept constants. These graphs evidenced that, for all three investigated nose radii of coated carbide inserts, it has produced more and more rough surfaces as the feed rates grow larger and larger. It has also been observed that the coated carbide insert with $\mathrm{N}_{\mathrm{r}}=$ $0.8 \mathrm{~mm}$ exhibited a little worse result than the other two groups of inserts. Using insert with $\mathrm{N}_{\mathrm{r}}=0.8 \mathrm{~mm}$, with the other conditions as used, we can expect the best $R_{a}=1 \mu \mathrm{m}$ keeping the feed rate is very low as low as $f=0.05-0.1$ $\mathrm{mm} / \mathrm{rev}$. The surface finish is crucially getting worse after the feed rate $\mathrm{f}=0.15 \mathrm{~mm} / \mathrm{rev}$ for uses of all three categories inserts for machining.

The above-mentioned rougher surface finish in Ti-6Al-4V alloy machining at higher feed rates can be explained by the rise of cutting forces causing increased level of vibrations in MFTW dynamic system of the machining processes and higher heat generation in the cutting zone. In relation to depth of cut (d) variation while keeping the cutting speeds and feed rates as constants, the surface roughness obtained in machining Ti-6Al-4V alloy, as depicted in graphs of Figure 7, using coated carbide cutting tools with several investigated nose radii, exhibited similar nature as the depth of cut. That means with the increment of depth of cut in each of the cases, the surface finish quality deteriorated, particularly crucial deterioration was observed beyond the depth of cut $d=1.2 \mathrm{~mm}$. The increased cutting forces with the increase of depth of cut may be responsible for increased vibration level in the MFTW dynamic system causing rougher surface finish.

\section{CONCLUSIONS}

An attempt to the roadmap of the cutting parameters $(\mathrm{V}, \mathrm{f}, \mathrm{d})$ optimisation for machining Ti-alloy Ti-6Al-4V using coated carbide tools with several cutting nose radii has been made successfully and valuable information on Ti-alloy cutting parameters has been revealed. The well-known real-life physical machining method has been re-introduced and used efficiently. The method provides more sensible and realistic outcomes in machining parameter optimisation in comparison to simulation-based optimisation. The results of real-life experiments in real-life situation for machining $\mathrm{Ti}-6 \mathrm{Al}-4 \mathrm{~V}$ using coated carbide inserts with mentioned geometry and three different nose radii have revealed the following valuable data. Regardless of nose radius $\left(\mathrm{N}_{\mathrm{r}}=0.4,0.8\right.$, and $\left.1.2 \mathrm{~mm}\right)$ investigated all three groups of coated carbide tools are capable to produce best surface finish, ranging between $R_{a}=0.5-1.0 \mu \mathrm{m}$, with cutting speed starting at $V=60 \mathrm{~m} / \mathrm{min}$ and beyond at least up to $V=250 \mathrm{~m} / \mathrm{min}$, as has been investigated, while keeping the feed rate and depth of cut as constants as $\mathrm{f}=0.1 \mathrm{~mm} / \mathrm{rev}$ and $\mathrm{d}=0.5 \mathrm{~mm}$.

The most important phenomenon has been observed that, though maximum cutting speed has been used was $V$ $=250 \mathrm{~m} / \mathrm{min}$, but the statistical tendency of the graphs (Figures 5-7) do not show any intention of worsening surface finish, it looks it would simply keep growing through a horizontal near-straight line. This phenomenon strongly suggests that high speed machining would be the most favourable way to machine Ti-6Al-4V using coated carbide tools for better productivity and cost effectiveness. This needs further research and experimentations on cutting tool materials and their physical properties. Also, studies on acceptable surface integrity obtained using higher cutting speed are equally essential.

As the cutting speed goes lower these investigated tools have produced more and more rough surface finish for the Ti-alloy. The graphs in Figures 5-7 evidenced that the cutting speeds little below $\mathrm{V}=50 \mathrm{~m} / \mathrm{min}$ the surface roughness values produced have gone as high as $R_{a}=1.4-3.5 \mu \mathrm{m}$ for the coated carbide tools with nose radii $N_{r}=$ 0.4 and $1.2 \mathrm{~mm}$, while the insert with $\mathrm{N}_{\mathrm{r}}=0.8 \mathrm{~mm}$ has produced rough surface no worse than $\mathrm{R}_{\mathrm{a}}=1.5 \mu \mathrm{m}$. Therefore, it is not suggested to use cutting speeds below $50 \mathrm{~m} / \mathrm{min}$ for all types of investigated cutting inserts of coated carbide. As the graphs in Figures 8-10 suggest, the best surface finish is possible to achieve using the feed rate $f=0.2 \mathrm{~mm} / \mathrm{rev}$ or lower; using feed rates beyond $\mathrm{f}=0.2 \mathrm{~mm} / \mathrm{rev}$ surface roughness values go crucially worse, as up to $\mathrm{Ra}=4.5 \mu \mathrm{m}$ for two of the cutting inserts $\left(\mathrm{N}_{\mathrm{r}}=0.4\right.$ and $\left.0.8 \mathrm{~mm}\right)$.

Similarly, surface roughness is highly affected by the increase of depth of cut beyond $\mathrm{d}=1.2 \mathrm{~mm}$. The graphs in Figures 11-13 suggest that using the values of depth of cut below $\mathrm{d}=1 \mathrm{~mm}$ the best surface finish can be expected, as good as $R_{a}=1.0-1.2 \mu \mathrm{m}$ for all three cutting tools with $\mathrm{N}_{r}=0.4 \mathrm{~mm}, 0.8 \mathrm{~mm}$, and $1.2 \mathrm{~mm}$. Hence, for the further research and industry practices it can be suggested that knowing the designated surface roughness given on the detail/part drawing of a component, the process designer have the wider liberty to choose the most suitable machining parameters to achieve the required surface finish for the product. Thus, the process design is the valuable 
and decisive stage of manufacturing to produce parts within the least possible production cost with the best possible product quality.

The quality of post-machined parts is assessed not only by the surface roughness but also by the surface integrity and geometric accuracy of the machined parts. As well, the scientific research on machinability of materials can only be sensible/profitable if the samples for experimentation are produced using the optimal cutting regimes. More research is essential for sub-layer residual stresses analysis and the microhardness of the machined sub-layer portions of the machined parts. A compromised set of machining conditions can only be drawn analysing the data obtained by the cutting parameters optimisation, sub-layer residual stress level and microhardness analytical data. While this compromised set of machining conditions is supposed to yield fruitful solutions for Ti-alloys machining.

\section{REFERENCES}

Ancio, F., Gamez, A.Z., Marcos, M. (2015). Factors influencing the generation of machined surface. Application to turned pieces. Journal of Materials Processing Technology, 215, 50 - 61.

Aspinwall, D.K., Dewes, R.C., Mantle, A.L. (2005). The machining of $y$-TiAl intermetallic alloy. CIRP Annals: Manufacturing Technology, 54 (1), 99-104.

Astakhov, P.V. (1999). Metal Cutting Mechanics. CRC Press LLC.

Ataollah J., Ulfried R., Wilfried E. (2008). The effect of machining on surface integrity and fatigue life. International Journal of Fatigue, 30, 2050 - 2055.

Che-Haron, H., Jawaid, A. (2005). The effect of machining on surface integrity of titanium alloy Ti-6\%Al-4\%V. Journal of Materials Processing Technology, 166, 188 - 192.

Davim, J.P. (editor) (2010). Surface Integrity in Machining. Springer, London.

Ezugwu, E.O., Bonney, J., Yamane, Y. (2003). An overview of machinability of aeroengine alloys. Journal of Materials Processing Technology, 134, 233 - 253.

Ezugwu, E.O., Wang, Z.M. (1997). Titanium alloys and their machinability - a review. Journal of Materials Processing Technology, 68, 262-274.

Gatto, A., Iuliano, L. (1997). Advanced coated ceramic tools for machining superalloys. International Journal of Machine Tools and Manufacture, VI. 37 (5), 591- 605.

Hua, J., Shivpuri, R. (2004). Prediction of chip morphology and segmentation during the machining of titanium alloys. Journal of Materials Processing Technology, 150, 124 -133.

Lei, S., Liu, W. (2002). High-speed machining of titanium alloys using driven rotary tool. International Journal of Machine Tools and Manufacture, 42, 653 - 661.

Machado, R., Walbank, J. (1990). Machining of titanium and its alloys - a review. Part B: Journal of Engineering Manufacture, 204 (B1), 53 - 60.

Nabhani, F. (2001). Machining of aerospace titanium alloys. Robotics and Computer Integrated Manufacturing, Vol. 17, pp. 99 - 106.

Ogedengbe, T. S. (2019). Sustainable Machining Processes Through Optimisation of Process Parameters. International Journal of Engineering Materials and Manufacture, 4(1), 22 - 26.

Pervaiz, S., Rashid, A., Deiab, I., Nicolescu, M. (2014). Influence of Tool Materials on Machinability of Titanium- and Nickel-based alloys: A Review. Materials and Manufacturing Processes, 29, 219 - 252.

Kuttolamadom, M., Jones, J., Mears, L., Oehsen, J. V., Kurfess, T., Ziegart, J. (2017). High performance computing simulation to identify process parameter designs for profitable titanium machining. Journal of Manufacturing Systems, 43, $235-247$.

Rahman, M., Wong, Y.S., Zareena, A.R. (2003). Machinability of Titanium Alloys. JSME International Journal. Series C, 46 (1), 107-115

Ribeiro, M.V., Moreira, M.R.V., Ferreira, J.R. (2003). Optimisation of titanium alloy machining. Journal of Materials Processing Technology, 458 - 463.

Schneider, F., Bischof, R., Kirsch, B., Kuhn, C., Muller, R., Aurich, J. C. (2016). Investigation of Chip Formation and Surface Integrity when micro-cutting cp-Titanium with ultra-fine grain cemented carbide. Procedia CIRP, 45, 115-118. Ulutan, D., Ozel, T. (2011). Machining induced surface integrity in titanium and nickel alloys: A review. International Journal of Machine Tools and Manufacture, 51, 250-280.

Veiga, C., Davim J.P., Loureiro, A.J.R. (2012). Properties and applications of titanium alloys: a brief review. Reviews on Advanced Materials Science, 32, 133 - 148.

Villeta M., Rubio E.M., Saenz De Pipaon J.M., Sebastian M.A. (2011). Surface finish optimization of magnesium pieces obtained by dry turning based on Taguchi techniques and statistical tests. Materials and Manufacturing Processes, 26, $1503-1510$

Yang, X., Liu, R. (2007). Machining titanium and its alloys. Machining Science and Technology: An International Journal, 3 (1), 107-139. 